\title{
Electrophysiological Analysis of Human Neocortex In Vitro: Experimental Techniques and Methodological Approaches.
}

\author{
M. Avoli, G.G.C. Hwa, G. Kostopoulos, A. Olivier and J.-G. Villemure
}

\begin{abstract}
In this review we summarize a number of technical and methodological approaches that have been used in our laboratory to study human brain slices maintained in vitro. The findings obtained in the course of these studies appear to be relevant in establishing the mechanisms that underlie physiological phenomena of the human brain such as synaptic plasticity or responses to neuroactive drugs. Moreover, these data are important for understanding certain fundamental mechanisms of epilepsy. In this respect, however, we caution that the mechanisms that apply to different forms of clinical epilepsy might be difficult to find given the variability present in the pathogenesis of human epilepsy.

RÉSUMÉ: Analyse électrophysiologique du néocortex humain in vitro techniques expérimentales et approches méthodologiques. Cet aperçu résume quelques modalités techniques et méthodologiques qui sont utilisées dans notre laboratoire pour l'étude in vitro de tranches de cerveau humain. Les constatations faites pendant ces études contribuent à définir certains mécanismes physiologiques du cerveau humain, tels que la plasticité synaptique ou les réponses aux médicaments neuroactifs. En plus, ces données éclaircissent de façon importante quelques mécanismes fondamentaux de l'épilepsie. À cet égard, cependant, nous prévenons que les mécanismes qui s'appliquent aux diverses formes de l'épilepsie clinique peuvent être difficiles à identifier, vu la variabilité qui existe parmi les facteurs pathogéniques de l'épilepsie humaine.
\end{abstract}

Can. J. Neurol. Sci. 1991; 18: 636-639

In the continuously growing field of neuroscience, the in vitro brain slice preparation has become one of the most powerful tools for exploring neuronal functions at the cellular level. Since the early 1970's the in vitro slice technique has also been adopted for studying the electrophysiological features of human neurons in samples obtained during surgical procedures. 1,2 Following these preliminary reports, more in depth studies on the cellular characteristics of human cortical cells have been undertaken. 3,4

Taking advantage of surgical procedures carried out for the relief of seizures as well as for other neurological conditions, we have performed in the last five years several experiments on slices of human neocortical tissue maintained in vitro. ${ }^{4-8}$ Here we shall summarize some technical aspects and methodological approaches that have been used in the study of human brain slices. In addition, we shall also briefly discuss some of our experimental findings obtained from each of the methodological approaches described.

\section{EXPERImental Methods and TeChniques}

The procedures used for preparing human neocortical slices have been described in detail in previous papers from our ${ }^{4}$ and other laboratories. ${ }^{3}$ They are diagrammatically illustrated in Figure 1A. Slices are cut from a small block of cortex removed during surgery and are maintained in an interphase tissue chamber and perfused with artificial cerebrospinal fluid (ACSF) at $35 \pm 1^{\circ} \mathrm{C}$. The ACSF composition can be modified depending upon the design of the experiment. Conventional intracellular and extracellular recordings, as well as measurements of extracellular ionic activity are performed as described in the rat cortex. ${ }^{9,10}$ Stimuli are applied through sharpened electrodes which are placed under visual control at different levels of the neocortical slice (i.e., underlying white matter, cortical layers or pia).

Three main categories of human neocortex can be analyzed in in vitro experiments. First, epileptogenic samples obtained from neo-cortical areas displaying active, interictal spiking in

From the Montreal Neurological Institute and Department of Neurology and Neurosurgery, McGill University, Montreal

Reprint requests to: M. Avoli, Room 804, Montreal Neurological Institute, 3801 University, Montreal, Quebec, Canada H3A 2B4 


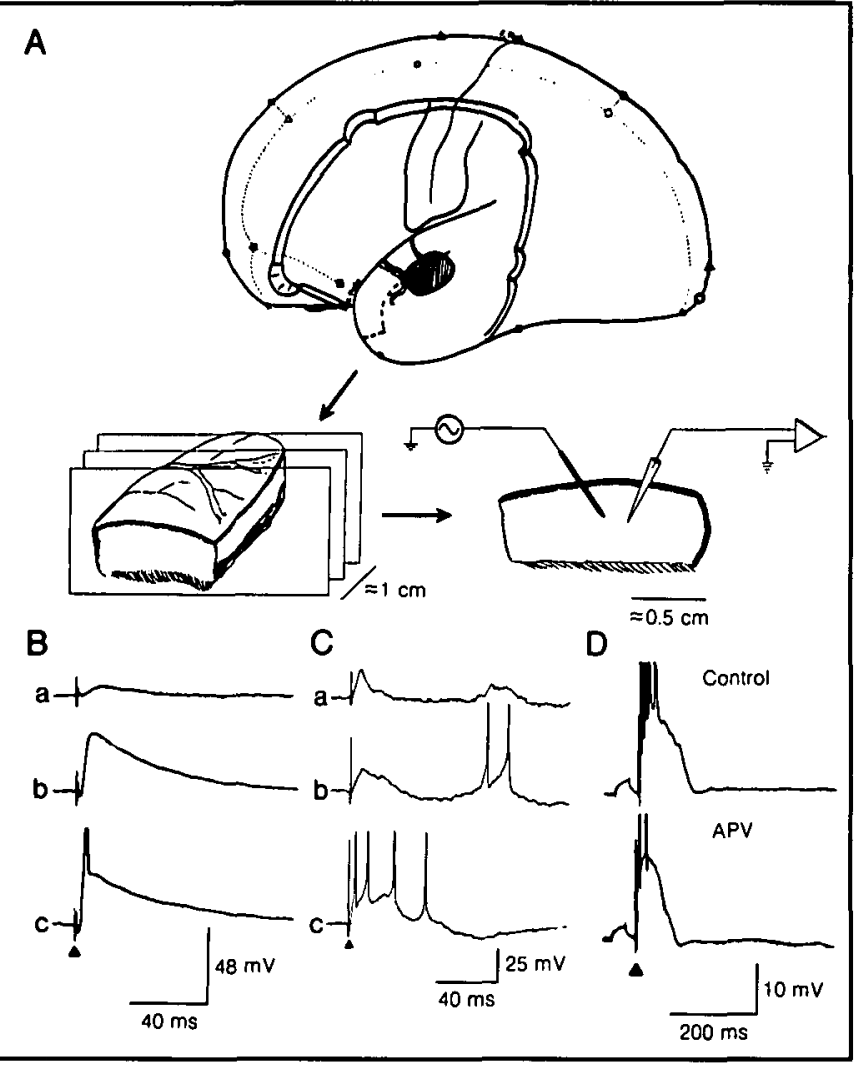

Figure 1 - A. Schematic illustration of the experimental procedures. A block of human brain tissue is excised from the temporal gyrus and cut into slices at a thickness 500-700 $\mathrm{m}$. The cellular features of the slice are examined with conventional intracellular and/or extracellular recordings techniques. B,C,D. Intracellular responses evoked by electrical stimulation of neocortical slices perfused with normal ACSF. Recordings from 2 different neurons in the same slice show that high intensity stimuli can generate an EPSP-single action potential sequence in one cell $(B)$ while eliciting burst firing of action potentials in another cell $(C)$. D. This type of stimulusinduced bursting is abolished by the NMDA receptor antagonist APV. C-D are from Avoli and Olivier 1989 with permission.

intra-operative electrocorticograms (ECoG). Second, juxtaepileptogenic samples, i.e. tissue excised from the lobe of epileptic patients, but not showing any sign of active spiking at ECoGraphy. Third, non-epileptogenic samples, i.e. neocortical tissue removed from non-epileptic patients undergoing neurosurgical procedures for pathologies other than epilepsy (e.g., tissue excised for providing access to a vascular malformation or a tumor). Slices from the tissue belonging to this last category are often used as "control" for comparative purposes. Therefore, care is taken in these cases to confirm that the patient had no clinical history of seizures and that pre-operative EEG and intra-operative ECOG were free of epileptiform discharges. However, one must make some reservations in this regard since epileptiform abnormalities, due to their intermittent occurrence, might not have been detected at the time when these diagnostic tests were performed. Further guidance in establishing the type of tissue is also provided by biochemical and histopathological studies which are performed on the samples used for the electrophysiological experiments. ${ }^{\prime \prime}$

\section{Methodological ApProaches and Experimental Findings}

There are at least three different methodological approaches that can be employed for analyzing the human neocortical tissue maintained in vitro. In most of the cases these approaches can be applied in the same series of experiments.

\section{The search for epileptiform bursting}

This approach probably represents the first type that was pursued in the human brain tissue maintained in vitro. ${ }^{1}$ It is an attempt to demonstrate that human neurons obtained from cortical structures which generate epileptiform activities in situ, do retain this type of epileptiform discharge when maintained in vitro. The rationale behind this type of approach rests on two main sets of findings. First, it has been shown in earlier studies that cells recorded in situ with extracellular recording techniques during surgical procedures for the relief of seizures do generate bursts of action potentials. ${ }^{13}$ Second, experiments performed in many models of epilepsy have indicated that experimentally-induced interictal and ictal discharges consist of prolonged bursts of action potentials. ${ }^{14}$ Therefore, in those studies in which this approach has been used, 2.3.14 extracellular and intracellular recordings have been employed to search for epileptiform activity in human epileptogenic tissue maintained in vitro. It was hoped that it might be possible to detect evidence that the paroxysmal depolarization shift (PDS) is the intracellular counterpart of the interictal EEG spike recorded in the experimental focus induced by chemical convulsants (see for review ${ }^{13,15}$ ).

It has been reported that human neurons obtained from the epileptogenic and juxta-epileptogenic samples, when maintained in vitro, have the ability to generate bursts of action potential discharges. ${ }^{1-4,7,14}$ However, the electrophysiological features of these bursting responses are quite different from the classical PDS; 13 (also, see below). First, the in vitro human burst is not a population event that is synchronously generated within the slice. Second, unlike the PDS, the human burst is not an all-ornone phenomenon and its activation is dependent upon the strength of the stimulus. Both of these aspects are illustrated in Figure $1 \mathrm{~B}$ and $\mathrm{C}$ where intracellular recordings were obtained from two different neurons located in the deep layers of the same slice. It is evident that following extracellular stimuli delivered at high strength the cell in panel $B$ generates a normal EPSP-single action potential sequence while the neuron of panel $C$ displays a burst of action potentials.

Despite these discrepancies when compared with the PDS, stimulus-induced bursts evoked in the human epileptogenic neocortex by electrical stimuli are characterized by an interesting pharmacological feature. They are reduced and eventually abolished by application of the N-methyl-D-aspartate (NMDA) receptor antagonist DL-2-amino-5-phosphovalerate (APV) (Figure 1D). Such an effect is not observed when APV is tested on the EPSP-single action potential sequence indicating that in these bursts NMDA-activated conductances participate in a type of synaptic potential that is not commonly observed in the normal, non-epileptic mammalian neocortex. Therefore these results suggest that the NMDA receptor might play a role in human epileptogenesis. The role played by NMDA receptors in "chronic" epileptogenesis has also been obtained in the kindling model of epilepsy in which a chronic epileptic focus is produced by daily electrical stimulation of certain brain structures. ${ }^{16}$ 
A major hurdle that this type of approach has to confront is the availability of proper "control" samples. Obviously, the occurrence of stimulus-induced bursts is a reflection of a state of hyper-excitability in the epileptic samples. However, whether this is indeed a marker of epileptogenicity will require further comparison with the non-epileptic (control) samples. A large number of control data will be necessary before one can draw any solid conclusion on this matter.

\section{The "species" approach}

Human brain tissue can also be used for validating some of the mechanisms that have been shown to be associated with synaptic and non-synaptic potentials in the forebrain structures of lower mammals. For instance, we have studied in cells located in the deep layers of the human neocortex the ionic mechanisms underlying the long-lasting afterhyperpolarization (AHP) which follows the repetitive firing induced by an intracellular pulse of depolarizing current. This AHP is presumably caused by an increased conductance to $\mathrm{K}^{+}$and is dependent upon the entry of $\mathrm{Ca}^{2+}$ into the cell, since it is recorded with $\mathrm{KCl}$-filled microelectrodes and is blocked by the perfusion of ACSF containing $\mathrm{Cd}^{2+}$ (Figure $2 \mathrm{~A}$ ) or $\mathrm{Mn}^{2+}$. As illustrated in Figure 2Aa, the effects of extracellular application of $\mathrm{Cd}^{2+}$ on the human neocortical neuron include a blockade of the AHP and the spontaneously occurring hyperpolarizing synaptic potentials

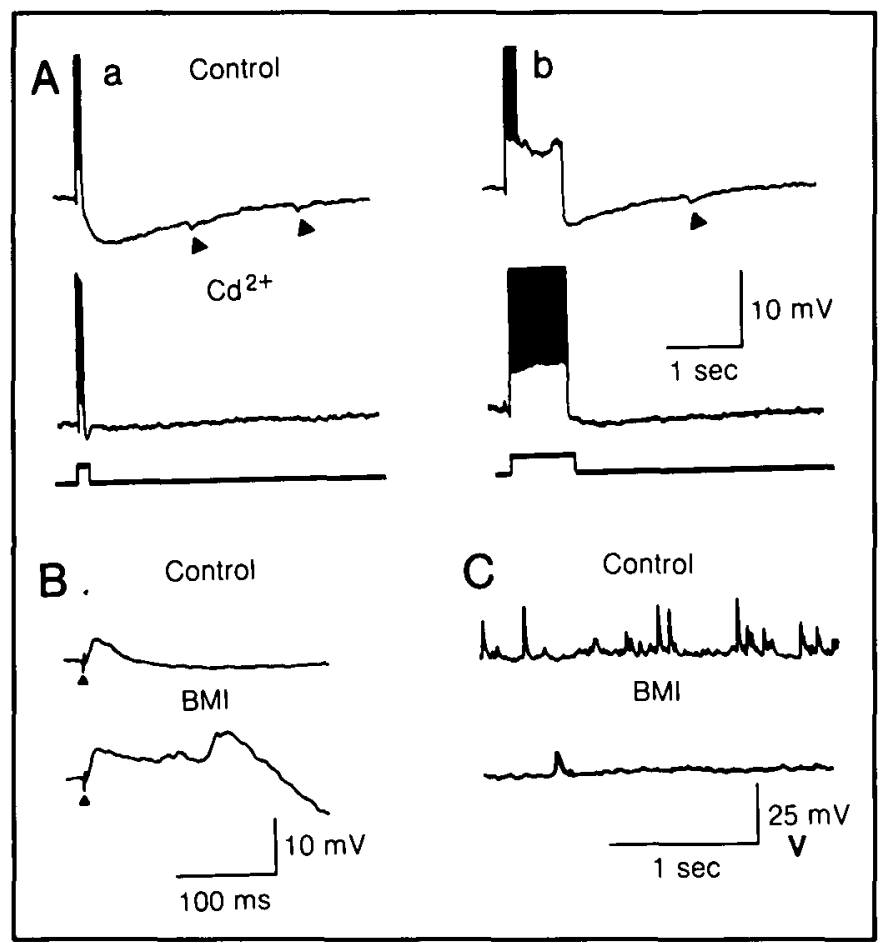

Figure $2-A$. Extracellular application of $\mathrm{Cd}^{2+}+(2 \mathrm{mM})$ modifies the AHP induced by pulses of depolarizing currents $(0.8 \mathrm{nA})$ of 2 different durations $(a, b) . C d^{2}+$ blocks the medium and late $A H P$ while unmasking the early $A H P(A a)$. This reduction of the $A H P$ reduces the adaptation of repetitive firing evoked by a long pulse of depolarizing current (Ab). From Avoli and Olivier 1989 with permission. $B, C$. Inhibitory mechanisms are operant in the epileptic human neocortical slice. IPSP that is sensitive to $G A B A_{\mathrm{A}}$ receptor antagonist $B M I$ can be observed following synaptic stimulation $(B)$ or might occur spontaneously $(C)$. (arrows). In addition, $\mathrm{Cd}^{2+}$ also hampers the ability of the cell to adapt during a prolonged pulse of depolarizing current (Figure $2 \mathrm{Ab}$ ). All these phenomena are similar to those occurring in the cat ${ }^{17}$ and guinea pig neocortical cells. 18

By using this approach it has also been shown that conductances activated through the $\mathrm{GABA}_{\mathrm{A}}$ and $\mathrm{GABA}_{\mathrm{B}}$ receptor subtypes underly the inhibitory postsynaptic potentials (IPSP) evoked in the human neocortex ${ }^{4,6,20}$ As shown in Figure 2B, the IPSP that follows the early EPSP elicited by focal electrical stimuli is blocked by the competitive $\mathrm{GABA}_{\mathrm{A}}$ receptor antagonist bicuculline methiodide (BMI). Furthermore, BMI also blocks the spontaneously occurring depolarizing GABAergic potentials which can be recorded with $\mathrm{KCl}$ filled microelectrode (Figure $2 \mathrm{C}$ ). These findings are in line with the results obtained by Schwartzkroin and Haglund 20 in cortical neurons studied in vitro in slices of mesial temporal structures removed from epileptic patients. Taken together, these electrophysiological data indicate that GABAergic potentials are present in the human epileptogenic cortex and thus suggest that a decreased efficacy of inhibitory mechanisms is unlikely to be an important factor in human epilepsy.

\section{The "experimental" model approach}

In line with the second methodological approach described, human cortical slices can be subjected to experimental procedures similar to those used in the animal cortex to elicit epileptiform activity. Two different outcomes might be anticipated from this type of experiments. First, it is possible to verify whether the experimental conditions employed for inducing epileptiform activity in animal brain do indeed work in the human brain. By doing so we should also be capable of testing directly in human brain tissue some of the hypotheses developed on the basis of animal experimentation. Second, it might be possible to understand whether in "extreme" situations such as the one accompanying the generation of epileptiform discharges induced by pharmacological manipulation, human neurons differ in their basic functions from those of lower mammals.

This type of experimental approach is shown in the three different experiments illustrated in Figure 3. As shown in panel A, human neocortical neurons generate epileptiform discharges following electrical stimuli during perfusion with the $\mathrm{GABA}_{\mathrm{A}}$ antagonist BMI. These discharges are similar in shape to the ones observed in the rat or guinea pig neocortex; ${ }^{14}$ however they are often followed by a pronounced afterdischarge which is rarely observed in the neocortex of lower mammals treated with BMI. This response is blocked by NMDA receptor antagonists (Figure 3A, APV). Epileptiform activity can be also elicited by perfusing the human neocortical slices with ACSF that virtually contains no $\mathrm{Mg}^{2+}$ (Figure 3B,C). 5,8 It should be emphasized that although epileptiform discharges are induced by $\mathrm{Mg}^{2+}-$ free ACSF in the rat neocortex, those observed in the human neocortex are more prolonged. Furthermore we have demonstrated that the human epileptogenic neocortex is characterized by an endogenous purinergic mechanism that is capable of controlling epileptiform discharges occurring in $\mathrm{Mg}^{2+}-$ free medium (Figure $3 \mathrm{C}$ ) ${ }^{8}$

\section{Conclusions}

The main purpose of this review has been that of considering the different methodological approaches that one can use when analyzing the human neocortical tissue maintained in vitro. 


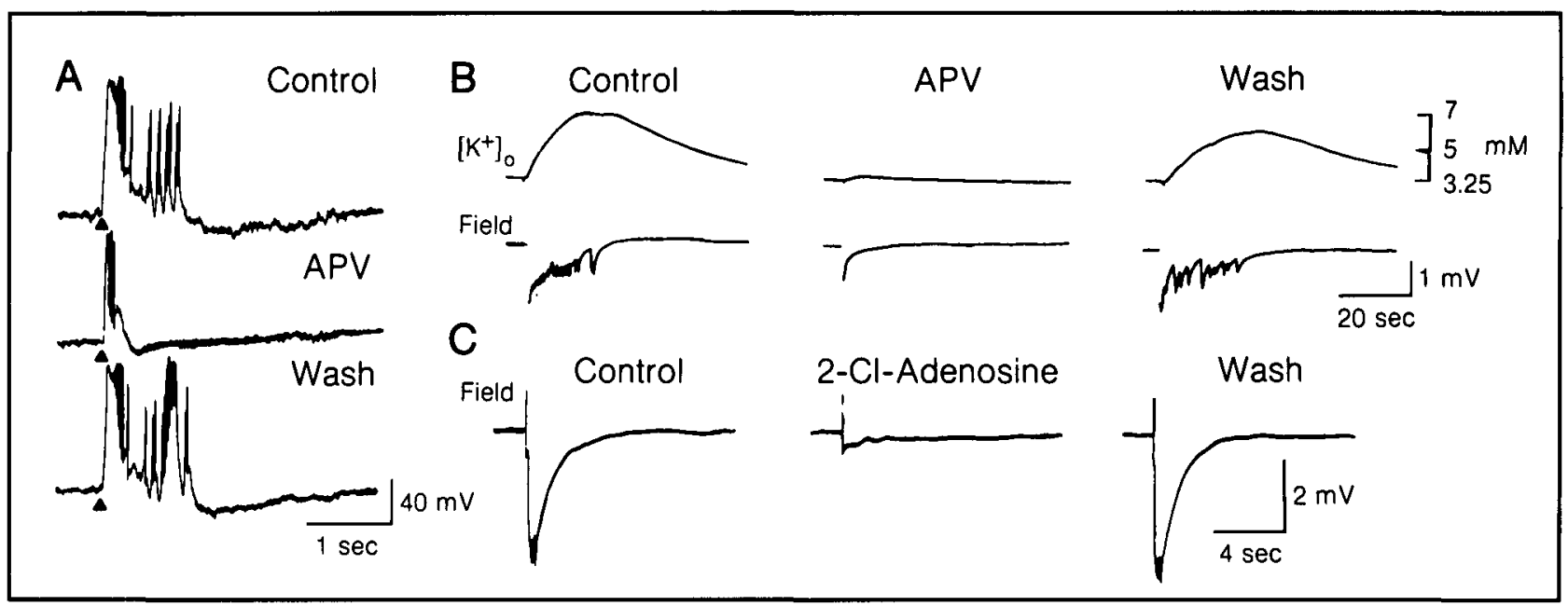

Figure 3 - Pharmacological manipulations of the human neocortical slice with ACSF that contains BNI $(A)$ or zero-Mg2+ $(B, C)$ evokes epileptiform activities. These epileptiform discharges are either reduced $(A)$ or abolished by the NMDA receptor antagonist APV $(B)$. The $\mathrm{Mg}^{2+}-$ free epileptiform discharges is also depressed by 1 -Cl-adenosine $(C)$.

Most of the findings obtained in the course of these studies are relevant for establishing the mechanisms that underlie physiological phenomena of the human brain such as synaptic plasticity and responses to neuroactive drugs. The core of the findings obtained to date is related however to the mechanisms of epilepsy. Indeed, while a number of animal models have been studied in the last three decades and while we have learned a great deal by doing so, the extent to which the cellular and pharmacological mechanisms observed in these experimental studies apply to human epilepsy still remains unknown. Undoubtedly the study of human tissue removed during neurosurgical procedures for intractable epilepsy is providing some of the information necessary to interpret the mechanisms underlying human epileptogenesis on the one hand and the available animal data on the other. The recent findings reviewed in this paper are promising although one should expect that mechanisms that generally apply to different forms of epilepsy might be difficult to find given to variability in the pathogenesis of human epilepsy. Further insight into what electrophysiological changes might be related to human epileptogenesis might be derived from a correlation of electrophysiological data with results obtained from studying biochemical changes, second-messenger mechanisms and histochemical alterations applied to the same sample of tissue removed during surgery.

\section{ACKNOWLEDGEMENTS}

The studies reported here were funded by the Medical Research Council of Canada (MA-8109 to MA). We thank Drs. J. Louvel, P. Perreault, R. Pumain and C. Drapeau for participating in some of the experiments reviewed here.

\section{REFERENCES}

1. Kato H, Ito Z, Matsuoka S, et al. Electrical activities of neurons in the sliced human cortex in vitro. Electroenceph Clin Neurophysiol 1973; 35: 457-462.

2. Schwartzkroin PA, Prince DA. Microphysiology of human cerebral cortex studied in vitro. Brain Res 1976; 115: 497-500.

3. Schwartzkroin PA, Turner DA, Knowles WD, et al. Studies of human and monkey "epileptic" neocortex in the in vitro slice preparation. Ann Neurol 1983; 13: 249-257.
4. Avoli M, Olivier A. Electrophysiological properties of synaptic responses in the deep layers of the human epileptogenic neocortex in vitro. J Neurophysiol $1989 ; 61: 589-606$.

5. Avoli M, Louvel J, Pumain R, et al. Seizure like discharges induced by lowering $\left[\mathrm{Mg}^{2+}\right]_{0}$ in the human epileptogenic neocortex maintained "in vitro". Brain Res 1987; 417: 199-203.

6. Avoli $M$, Perreault $P$, Olivier A, et al. 4-aminopyridine induces a long-lasting depolarizing GABA-ergic potential in human neocortical and hippocampal neurons maintained "in vitro". Neurosci Lett 1988; 94: 327-331.

7. Avoli M, Olivier A. Bursting in human epileptogenic neocortex is depressed by an N-methyl-D-aspartate antagonist. Neurosci Lett 1987; 76: 249-254.

8. Kostopoulos G, Drapeau C, Avoli M, et al. Endogenous adenosine can reduce epileptiform activity in the human epileptogenic cortex maintained in vitro. Neurosci Lett 1989; 106: 119-124

9. Avoli M. Inhibitory potentials in neurons of the deep layers of the in vitro neocortical slice. Brain Res 1986; 370: 165-170.

10. Pumain R, Heinemann U. Stimulus- and amino acid-induced calcium and potassium changes in rat neocortex. $\mathrm{J}$ Neurophysiol 1984; 53: 1-16.

11. Sherwin AL. Guide to neurochemical analysis of surgical specimens of human brain. Epilepsy Res 1988; 2: 281-288.

12. Wyler AR, Ward AA Jr. Neuronal firing patterns from epileptogenic foci of monkey and human. In: Delgado-Escueta A, et al.. eds. Advances in Neurology. New York: Raven Press 1986, vol. 44: 967-989.

13. Prince DA, Connors BW. Mechanisms of interictal epileptogenesis. In: Delgado-Escueta A, et al., eds. Advances in Neurology. New York: Raven Press 1986, vol. 44: 275-299.

14. Prince DA, Wong RKS. Human epileptic neurons studied in vitro. Brain Res 1981; 210: 323-333.

15. Ayala GF, Dichter M, Gumnit RJ, et al. Genesis of epileptic interictal spikes. New knowledge of cortical feedback systems suggests a neurophysiological explanation of brief paroxysms. Brain Res 1973; 52:1-17.

16. Mody I, Heinemann U. NMDA receptors of dentate gyrus granule cells participate in synaptic transmission following kindling. Nature Lond 1987; 326: 701-704.

17. Schwindt PC, Spain WJ, Foehring RC, et al. Multiple potassium conductances and their functions in neurons from cat sensorimotor cortex in vitro. J Neurophysiol 1988; 59: 424-449.

18. Hotson JR, Prince DA. A calcium-activated hyperpolarization follows repetitive firing in hippocampal neurons. J Neurophysiol 1980; 43: 409-419.

19. McCormick DA. GABA as an inhibitory neurotransmitter in human cerebral cortex. J Neurophysiol 1989; 62: 1018-1027.

20. Schwartzkroin PA, Haglund MM. Spontaneous rhythmic synchronous activity in epileptic human and normal monkey temporal lobe. Epilepsia 1986; 27: 523-533. 